Document downloaded from:

http://hdl.handle.net/10251/39739

This paper must be cited as:

Campos Sánchez, I.; Bataller Prats, R.; Gandía Romero, JM.; Soto Camino, J.; Martínez Mañez, R.; Gil Sánchez, L. (2013). Monitoring grape ripeness using a voltammetric electronic tongue. Food Research International. 54(2):1369-1375. doi:10.1016/j.foodres.2013.10.011.

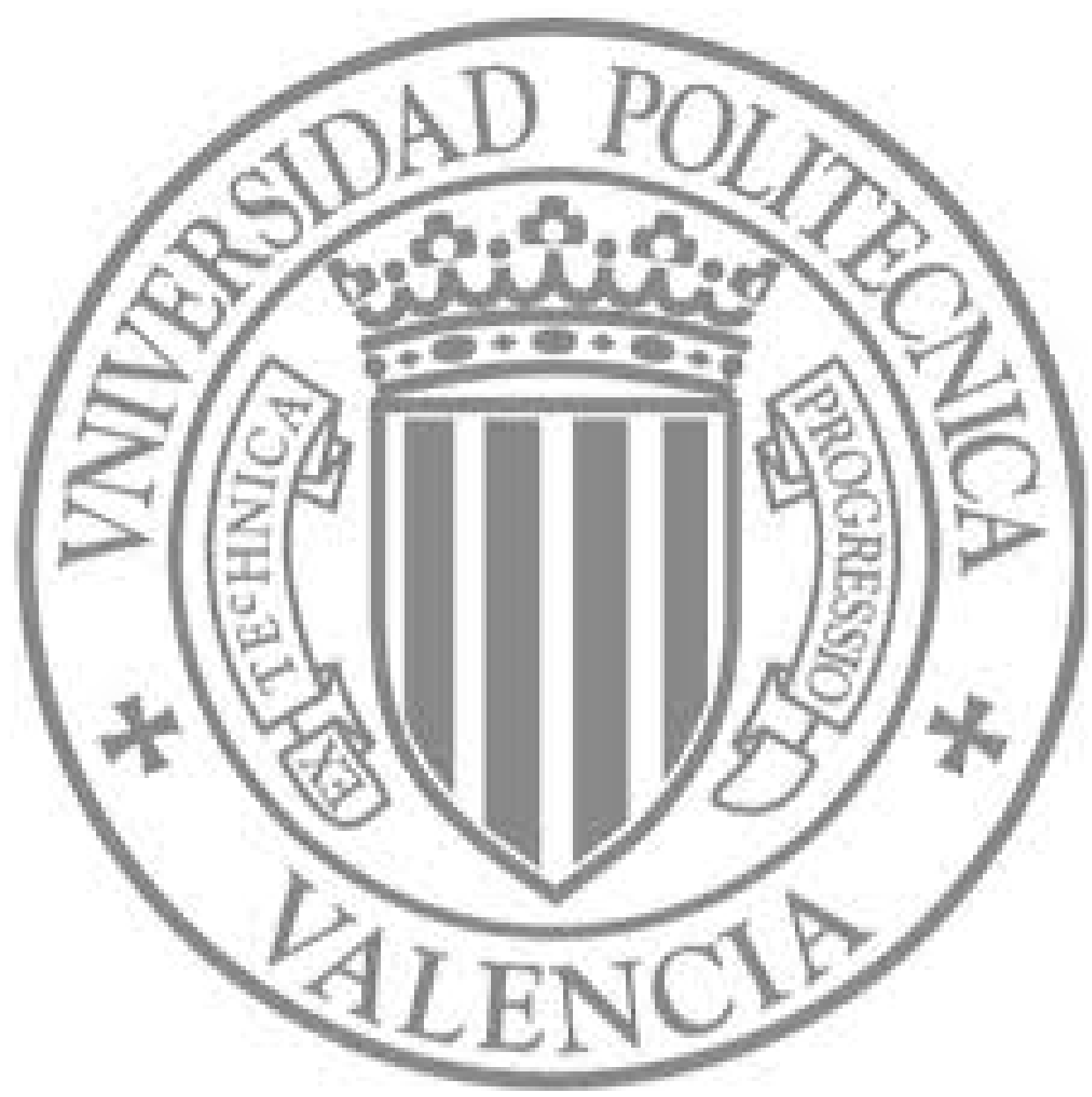

The final publication is available at

http://dx.doi.org/10.1016/j.foodres.2013.10.011

Copyright Elsevier 


\title{
Monitoring grape ripeness using a voltammetric electronic tongue
}

\author{
Inmaculada Campos ${ }^{1,2,6}$, Román Bataller ${ }^{1}$, Raquel Armero ${ }^{3}$, José Manuel Gandia ${ }^{1,4}$, \\ Juan Soto ${ }^{1,2}$, Ramón Martínez-Máñez ${ }^{1,2,6^{*}}$ Luis Gil-Sánchez ${ }^{1,5}$ \\ ${ }^{1}$ Centro de Reconocimiento Molecular y Desarrollo Tecnológico (IDM), Unidad \\ Mixta Universidad Politécnica de Valencia - Universidad de Valencia, Valencia, \\ Spain. \\ ${ }^{2}$ Departamento de Química. Universidad Politécnica de Valencia. Camino de Vera \\ s/n. E-46022, Valencia, Spain. \\ ${ }^{3}$ TorreOria. Ctra. Pontón-Utiel km 3. 46390 Requena, Spain. \\ ${ }^{4}$ Departamento de Construcciones Arquitectónicas. Universidad Politécnica de \\ Valencia. Camino de Vera s/n, E-46022, Valencia, Spain. \\ ${ }^{5}$ Departamento de Ingeniería Electrónica. Universidad Politécnica de Valencia. \\ Camino de Vera, s/n, E-46022, Valencia, Spain. \\ ${ }^{6}$ CIBER de Bioingeniería, Biomateriales y Nano medicina (CIBER-BBN). \\ *Author corresponding mail: rmaez@qim.upv.es, Telf: 0034963877343
}

\begin{abstract}
The use of a voltammetric electronic tongue as a tool to monitor grape ripeness is proposed herein. The electronic tongue consists of eight metallic electrodes housed inside a stainless steel cylinder. The study was carried out over a period of ca. 1 month (August 2012) on different grape varieties (Macabeo, Chardonnay, Pinot Noir, Cabernet Sauvignon, Shyrah, Merlot and Bobal) from various vineyards near Requena and Utiel (Valencia, Spain). Apart from the electrochemical studies, the physicochemical parameters, such as, Total Acidity, $\mathrm{pH}$ and ${ }^{\circ}$ Brix, were also determined in
\end{abstract}


grapes. The PCA models, obtained using the physico-chemical or electrochemical data, showed variation of ripeness with time. Moreover the study was completed by using partial least squares (PLS) regression in an attempt to establish a correlation between the data collected from the electronic tongue and Total Acidity, $\mathrm{pH}$ and ${ }^{\circ}$ Brix values. A good predictive model was obtained for the prediction of Total Acidity and ${ }^{\circ}$ Brix. These results suggest the possibility of employing electronic tongues to monitor grape ripeness and of, therefore, evaluating the right time for harvesting.

Keywords: electronic tongue, grape ripeness, total acidity, Brix.

\section{Introduction}

During wine production, the composition of grapes at the time of picking is an important parameter which may be considered the most crucial decision in winemaking. While grape ripen, some complex physicochemical and biochemical processes occur, such as the continuous rising and lowering of sugar concentrations and acid levels, respectively, which are also influenced by genetic, climatic and geographical factors, and by cultural practices (González-Sanjosé et al., 1991; Palacios et al., 1986; Andrades \& González-Sanjosé, 1995; Jones \& Davis, 2000). All these defining the ripeness process determine grape quality and the time of harvesting for winemaking. Traditionally, harvesting date indicators have been determined by parameters such as berry weight, must density (Coombe, 1987) and the relation between sugars content and Total Acidity (Peynaud, 1989; King et al., 1988; Robredo et al., 1991). Nowadays, Near Infrared Spectroscopy (NIRS) has also been reported as a suitable technique capable of measuring parameters such as sugar content (Fernández-Novales, 2009), pH value (Larraín, Guesalaga \& Agosin, 2008) and acidity (Chauchard, 2004) in grapes. All these 
procedures imply the use of instrumentation. In fact, even one of the simplest traditional Total Acidity, requires the use of a refractometer and an automatic titration system (or manual titrations) which employs chemical products (Jackson, 2000). Moreover, other techniques, such as Near Infrared Spectroscopy (NIRS), require expensive instrumentation and complex calibration (Ferrer-Gallegoa, 2013). In this context, the possibility of designing alternative methods to monitor grape ripeness (an important factor to determine when to harvest) simply and rapidly may be of importance.

From another point of view, an electronic tongue is a device that produces a signal which can be correlated with taste when properly calibrated. Besides, there are many electronic tongues capable of identifying and classifying liquid samples, and of predicting or quantifying the concentration of particular substances or taste attributes (Ciosek \& Wróblewski, 2007). In the last few years, electronic tongues have made the best of different measuring principles, including potentiometry, voltammetry and amperometry (Del Valle, 2010). They have also been constructed on the basis of optical and mass sensors (Zhang \& Turner, 2005). Electronic tongues are usually composed of an array of chemical sensors coupled to a pattern recognition analysis. Another aim in electronic tongues development is to design easy-to-use reduced-in-size systems applicable for in-situ and at-site monitoring. A number of studies has described the use of such sensor arrays to analyze foodstuffs (Scampicchio et al., 2008; Gallardo, Alegret \& Del Valle, 2005) pharmaceutical samples (Lorenz et al., 2009; Wilson \& Baietto, 2011), clinical samples (Gutierrez, Alegret \& Del Valle, 2007; Lvova et al., 2009) and environmental monitoring (Rudnitskaya et al., 2009; Mimendia et al., 2010). Moreover, the literature includes some works which apply electronic tongues to grapes and to wine samples. For instance, electronic tongues have been used to monitor both post-harvest 
grape dehydration (Santonico et al., 2010; Buratti et al., 2011) and wine aging (Apetrei et al., 2013; Gay et al., 2010). Besides, attempts have also been made to correlate electronic tongues data with traditional human sensory perception of wine attributes (Legin et al., 2003) or to quantify the presence of grape varieties in wines (Gutierrez et al., 2011; Buratti et al., 2012). Recently, electronic tongues have been also employed to determine concentrations of chemical compounds in wine, such as sulfites (Kirsanov et al., 2012), polyphenols and different sugars (Cetó et al., 2012; Pigani et al., 2011). As far as we know, no studies on the potential use of electronic tongues for grape ripeness monitoring or for determining harvesting dates have been reported.

Following our interest in the development of sensing systems and probes (Martínez-Máñez \& Sancenón, 2006), and given our experience in designing electronic tongue devices for several applications (Labrador et al., 2009; Campos et al., 2010; Campos et al., 2012), we report herein the development of an electronic tongue based on simple metallic electrodes and voltammetry, and its use to characterize grape ripeness. This research aims to demonstrate the potential use of this electronic tongue to determine the Total Acidity and ${ }^{\circ}$ Brix parameters that are related with grape ripeness, which is traditionally used to determine the harvesting date.

\section{Experimental}

\subsection{Samples preparation}

The study into the ripeness process was carried out on seven grape varieties (Macabeo, Chardonnay, Pinot Noir, Cabernet Sauvignon, Shyrah, Merlot and Bobal) over a period of ca. 1 month (August 2012), which were sampled every 2 days (11 sampling days in all) from different vineyards near Requena and Utiel (Valencia, Spain). The final number of samples was 68 , which were less than the total expected 
samples (11 sampling days x 7 grape varieties) because the harvest of same varieties took place before the studies finished. After collection and crushing, and after waiting for $5 \mathrm{~min}$, samples were decanted to separate the juice from the pulp. During the grapes monitoring period, the average daily temperature was between $35^{\circ} \mathrm{C}$ and $40^{\circ} \mathrm{C}$, and precipitation during this time was practically zero $\left(\right.$ ca. $0.51 / \mathrm{m}^{2}$ ).

\subsection{Physicochemical characterization.}

For the purpose of controlling grape ripeness, three chemical parameters; i.e., Total Acidity, $\mathrm{pH}$ and sugar content $\left({ }^{\circ} \mathrm{Brix}\right)$; were determined. Total acidity was calculated by titration with $\mathrm{NaOH} 0.5 \mathrm{~N}$ using a pHmeter (Crison Titromatic $2 \mathrm{~S} 3 \mathrm{~B}$, Spain). This equipment was also used to determinate $\mathrm{pH}$. Sugar content was determined with a manual refractometer (Zuzi 300, Spain).

\subsection{The Electronic Tongue}

\subsubsection{The Electronic System}

The system used in the electronic tongue was developed by the Centre of Molecular Recognition and Technological Development (IDM) at the Polytechnic University of Valencia. The system consists of electronic equipment and a software application that runs on a PC. The system included a potentiostat which applies voltage to the electrochemical cell and measures both the voltage and current at the working electrodes. The potentiostat permits measurements with up to eight multiplexed working electrodes. Briefly, the electronic equipment included a 16-bit microcontroller (PIC24FJ256), a 12-bit Digital-to-Analog converter (DAC), two 12-bit Analog-toDigital converters (ADC), a potentiostat that incorporated a current measurement circuit, a working electrode multiplexing block and a stabilization circuit. Some analog 
signal conditioning circuits were also used to adapt the signals connecting the potentiostat to the DAC and the ADC. The microcontroller received the data sent by the PC. After receiving all the data corresponding to a test, the microcontroller configured the current scale and the stabilization level of the potentiostat, and then selected the desired working electrode. Then it outputted the value corresponding to the temporal evolution of the signal to the DAC at a rate that fulfilled the signal timing requirements. In the same loop, the program of the microcontroller sampled the signals corresponding to the voltage and current flowing at the selected working electrode. The collected data were sent to the PC where they were processed and stored. Details of the characteristics of this electronic equipment have been published elsewhere (Alcañiz et al., 2012).

\subsubsection{Preparation of an E-Tongue}

The electronic tongue device consisted of an array of eight working electrodes (Au, $\mathrm{Pt}$, Ir, $\mathrm{Rh}, \mathrm{Ag}, \mathrm{Cu}, \mathrm{Ni}$, and $\mathrm{Co}$ ) with a purity of $99.9 \%$ and a $2 \mathrm{~mm}$ diameter from GOODFELLOW, which were housed inside two homemade stainless steel cylinders that were used at the same time as both the body of the electronic tongue system and the counter electrode. The different wire electrodes were fixed inside the cylinder using an epoxy RS 199-1468 polymer. The generation of pulses and recording current data were performed by the previously described electronic equipment. Traditionally, fouling is one of the major drawbacks that limits the application of electrochemical sensors. In this context, one advantage of using electronic tongues based on metallic electrodes is that it is quite simple to remove any accumulated unwanted material on the electrode by simply polishing the surface (Olsson, Winquist \& Lundström, 2006). This simple procedure helps obtain a clean new surface ready to be used after each, or after a certain number of, measurement(s). Before being used in this work, the electrode surface was 
prepared by mechanical polishing with emery paper and was rinsed with distilled water. Then the electrode was placed on a felt pad and was polished with $0.05 \mu \mathrm{m}$ alumina polish from BAS, washed with distilled water and polished again on a nylon pad with $15 \mu \mathrm{m}, 3 \mu \mathrm{m}$ and $1 \mu \mathrm{m}$ diamond polishes to produce a smooth, mirror-like electrode surface. Later while taking the series of measures, only simple diamond polishing was applied.

\subsection{Measurement procedure}

Every 2 days, samples of different grape varieties were collected early in the morning and were analyzed on the same day in the TorreOria laboratories. For each sample, traditional determinations were made (Brix, $\mathrm{pH}$ and Total Acidity), whereas at the same time, the electrochemical response of the sample was analyzed with the electronic tongue. Before the electrodes were used, they were polished. Having completed the measurement, the electronic tongue was switched off until the next samples arrived 2 days later. All the samples were measured with the electronic tongue under thermostatted conditions $\left(25.0 \pm 0.1^{\circ} \mathrm{C}\right)$.

\section{Insert here Figure 1}

In this study, we employed a Large Amplitude Pulse Voltammetry (LAPV) wave form (Winquist, Lundström \& Wide, 1999; Gutés et al., 2006). Figure 1A shows the applied pulse pattern, which consists of 40 pulses in a similar configuration to a staircase voltammetry, but with potential set to 0 after each increment. The pulse sequence was: $0,200,0,400,0,600,0,800,0,1000,0,800,0,600,0,400,0,200,0$, $200,0,-400,0,-600,0,-800,0,-1000,0,-800,0,-600,0,-400,0,-200,0,0,0,0$ 
$(\mathrm{mV})$. Each pulse was applied for $50 \mathrm{~ms}$. The increment for the potential steps was 200 $\mathrm{mV}$, and the maximum and minimum potentials were chosen in order to avoid water electrolysis phenomena. In all, 8000 values of current (25 points per pulse x 40 pulses $\mathrm{x}$ 8 electrodes) were recorded per sample. The time required to complete the measure with five iterations was only 2 seconds. The rate limiting step for data acquisition was actually the mechanical polishing of electrodes, which took about $5 \mathrm{~min}$ (for all eight electrodes). By way of example, Figure 1B illustrates the current measured for a Macabeo sample for the Pt (continuous line) or Ag electrodes (dotted line) when the pulse sequence was applied. The remaining noble electrodes ( $\mathrm{Rh}, \mathrm{Ir}$ and $\mathrm{Au}$ ) displayed a similar behavior to the platinum electrode, while the remaining non noble electrodes displayed a similar behavior to the silver electrode.

In all, 68 samples were measured. The calibration and validation samples were randomly selected. Each sample was measured 5 times and a mean value was calculated in a pre-processing step. For the noble electrodes, the typical value of the standard deviation within a sample did not usually exceed the value of $0.5 \mu \mathrm{A}$, although it was somewhat higher for the cobalt and nickel electrodes. When the standard deviation was higher than 0.5 , the data series was eliminated and replaced with data from a new repetition. The standard deviation value of $0.5 \mu \mathrm{A}$ corresponded to a mean error value of $1 \%$ in the reading. By using the electronic tongue described herein and applying this criterion, only two samples of 100 samples were discarded and replaced with new ones.

\subsection{Data management}

In order to show the electronic tongue's different responses to different samples, the voltammetric electrochemical response data were combined to form ensembles for 
pattern recognition in an attempt to discriminate samples. A multivariate data analysis (MVDA) was used for this purpose (Labrador et al., 2009).

\subsubsection{Principal Components Analysis (PCA)}

Typically, a PCA decomposes the primary data matrix by projecting the multidimensional data set onto a new coordinate base formed by the orthogonal directions with maximum data variance. The eigenvectors of the data matrix are called principal components and they do not intercorrelate because they are characteristic of each data matrix. The principal components (PCs) are ordered so that PC1 displays the largest amount of variance, followed by the next largest PC2, and so on. The main PCA features are the coordinates of the data in the new base (scores plot) and the contribution of the sensors to each component (loading plot) (Abdi \& Williams, 2010).

\subsubsection{Partial least squares (PLS)}

PLS regression is a technique that generalizes and combines features from the PCA and the multiple regression. Its goal is to predict or analyze a set of dependent variables (Y) from a set of independent variables or predictors (X) by the simultaneous decomposition of those matrices or vectors in a group of components (latent variables) which explain the covariance of $\mathrm{X}$ and $\mathrm{Y}$ as much as possible (Gelali \& Kowalski, 1986). Prediction models for the Total Acidity, $\mathrm{pH}$ and ${ }^{\circ} \mathrm{Brix}$ parameters were built by using the data collected from the electronic tongue in the calibration set. Prior to building the model, "leave-one-out" cross validation studies were performed to estimate the performance of the predictive model and to select the quantity of latent variables. The model obtained for these parameters was then applied to the set of validation samples. Model evaluation was carried out by comparing the real concentrations with 
the predicted ones from the PLS regression using the determination coefficient $\left(r^{2}\right)$, parameters $p 1, p 2$ (from $y=p 1 x+p 2$ ), and the root mean square error of prediction (RMSEP). All the statistical analyses were performed with the Solo application software (version 6.5, Eigenvector Research, Inc).

\section{Results and discussion}

\subsection{Grape ripeness and PCA plots.}

The Total Acidity, $\mathrm{pH}$ and ${ }^{\circ} \mathrm{Brix}$ parameters determined for the distinct grape varieties on the different sampling days are shown in Table S1 (see Supporting Information). Moreover, Figure 2 shows a plot of the Total Acidity and ${ }^{\circ}$ Brix data according to each grape variety and sampling date. By simply inspecting the experimental data, it is apparent that some parameters such as $\mathrm{pH}$ showed a relatively minor change (the $\mathrm{pH}$ values remained within the ca. 2.5-3.5 range). In contrast, other parameters such as Total Acidity displayed wider variation depending on time for a certain grape variety, and also between different grapes on a given day. Typically, acidity ranged from $20-30 \mathrm{~g} / \mathrm{l}$ on the first sampling days, to values lower than $10 \mathrm{~g} / \mathrm{l}$ when grapes were harvested. As expected, sugar content increased and ran in parallel to decreased total acidity. Moreover, the increase in the ${ }^{\circ}$ Brix values and its evolution also differed for the various grapes. As shown in Figure 2 and Table S1, at the end of August, all the grape varieties reached a ${ }^{\circ}$ Brix value of 23 , regardless of the initial value at the start of the study, except for grapes Macabeo and Chardonnay, which were harvested at $20^{\circ}$ Brix to manufacture cava. Besides, at the beginning of this study, some grapes such as Bobal, Shyrah, Pinot Noir and Chardonnay, were at a more advanced maturation stage (with ${ }^{\circ}$ Brix values of over 10) than the remaining grapes (i.e., Macabeo, Cabernet and Merlot) which started with lower ${ }^{\circ}$ Brix values. Despite these 
differences, the evolution of ripening for all the grapes generally ran in parallel, which was most likely caused by the close proximity between the vineyards where the grapes came from, and also because of the similar constant weather conditions (high temperatures and no precipitations), which contribute to a continuous ripeness process for all grapes. In fact, this ripeness evolution can be observed from the PCA score plots constructed from the physico-chemical data. Typically, a PCA decomposes the primary data matrix by projecting the multi-dimensional data set onto a new coordinate base formed by the orthogonal directions with data maximum variance. Here the PCA was used as a simple method to project data onto a two-dimensional plane. Figure 3A shows the PCA score plot from the Total Acidity, $\mathrm{pH}$ and ${ }^{\circ}$ Brix data for grapes Merlot, Cabernet Sauvignon and Bobal. The remaining grapes were omitted for clarity; however, they followed a similar trend in the PCA plot to that found for the represented grapes. In this plot, the two first principal components explained $99.18 \%$ of data variance. As shown, the grapes analyzed at the beginning of our study, which therefore presented low ripeness, (i.e., high Total Acidity values and low ${ }^{\circ}$ Brix values) are on the left of the PCA plot, whereas at the end of the study (before harvesting), samples are located on the right of the figure.

Figure 3B displays the PCA score plot from the data collected from the electrochemical studies acquired with the noble metal electrodes when using the electronic tongue also for grapes Merlot, Cabernet Sauvignon and Bobal. As in the above case, the remaining grape varieties were omitted for clarity, although they followed a similar trend. This PCA study reveals a high degree of dispersion among the independent dimensions created by the combinations of the electrochemical responses of the four electrodes used in these arrays (similar results were found when the whole set of electrodes was considered). For this plot, the first principal component explained 
only $46.30 \%$ of data variance, whereas the first two components represented $67.39 \%$ of total variance. In this case, a general trend is also observed. Low-ripeness grapes are positioned on the positive part of the PC1 axis, whereas the grapes obtained on the last days are located on the left of the plot. However, neither the PCA obtained from the physic-chemical data nor that from the electrochemical data was able to discriminate between grape varieties.

Insert here Figure 2 and Figure 3

The PCA plot obtained from the electronic tongue indicates that the electrochemical behavior of the grape samples changed as their ripeness was modified. This should relate with changes in Total Acidity and ${ }^{\circ}$ Brix (sugar content). These electrochemical variations may relate with the presence of redox-active species during the ripeness process. Moreover, it should be taken into account that lack of clear redox processes did not hamper the use of voltammetric electronic tongues. In fact, the electrochemical changes in the current response on different electrodes induced by chemical species (i.e., due to either changes in the electrodes' equilibrium potential of the electrodes or the adsorption of chemical species on the electrode) can also be used for multivariate data analyses. For instance, it is known that noble electrodes are capable of adsorbing organic substances. For example, the Pt electrode is able to adsorb a wide range of organic compounds on its surface; aromatics, heterocyclic aromatics, alcohols, phenols, sulfides, amides, aldehydes, carboxylic derivatives and esters, among others, all of which were present in grape juice, and may cause significant changes in the oxidation potential of the metal and in current intensity (Soriaga et al., 1985). Similar behaviors were noted for the iridium, rhodium and gold electrodes (Michelhaugh et al., 1991). 


\subsection{PLS models to quantify grape ripeness.}

Encouraged by the PCA results obtained, indicating that grape ripeness correlates with both the physico-chemical and voltammetric data, we completed our study by using partial least squares (PLS) regression in an attempt to establish a correlation between the data from the electronic tongue and the Total Acidity, $\mathrm{pH}$ and ${ }^{\circ} \mathrm{Brix}$ values. The Simple Partial Least Square (SIMPLS) algorithm, developed by Sijmen de Jong (De Jong, 1993), was used for the PLS. This method relies on the orthogonalization of a Krylof sequence to calculate PLS weights. An autoscale was used as the preprocessing method; prior to building the model, cross-validation was employed to evaluate the adequacy of the experimental data and to select the quantity of latent variables (three latent variables were used for this study). In order to test the tongue's real potential application to detect grape ripeness, a training/validation procedure was followed. To perform this task, we adopted a strategy which consisted in randomly drawing a group of data from the whole data set. The remaining data were used to conduct training in order to obtain the PLS coefficients. Moreover in a later step, the previously extracted data were utilized for validation purposes.

First a PLS model was built using 46 samples (the training set) from the electrochemical data obtained by the electronic tongue and the known Total Acidity, pH and ${ }^{\circ}$ Brix values. The PLS regression method was applied to the data using the whole set of electrodes, and by separately using the noble (Pt, $\mathrm{Rh}, \mathrm{Ir}$ and $\mathrm{Au}$ ) and non noble $(\mathrm{Cu}, \mathrm{Co}, \mathrm{Ag}$ and $\mathrm{Ni})$ electrodes. In a second step, the electrochemical data from 22 samples (validation set) were employed, and the Total Acidity, $\mathrm{pH}$ and ${ }^{\circ}$ Brix values for these samples were predicted by the PLS model. These predicted vs. real concentration data are plotted in Figure 4 for the predicted values obtained when using only the noble 
metal electrodes. For comparison purposes, the training data were also included. The figure allows a simple visual inspection of the accuracy and precision created in the prediction model. In fact, most of the data in the training (square) and validation (dots) sets appear along the reference line 1:1 (dotted line). If the predictions using PLS for the 22 samples were perfect, a line of slope 1 and an intercept with the $y$-axis of 0 would be obtained. Evidently, this is an ideal situation and, in fact, there were minor differences found between the predicted vs. the real concentration values. In this context, a simple way to analyze the PLS prediction for the 22 samples (the validation set) is to use a linear model (i.e., $y=\mathrm{p} 1 \mathrm{x}+\mathrm{p} 2$ ) in order to adjust the predicted vs. the real concentration data shown in Figure 4. This allowed to obtain parameters $p 1$ (slope of the fitting line) and $p 2$ (intercept with the y-axis). Moreover, parameter RMSEP (root mean square of prediction) was also determined. Parameters $p 1$ and $p 2$ are related with the accuracy in prediction, whereas RMSEP deals with model precision. Thus, the PLS model is better when the $p l$ value approaches 1 and when the RMSEP value comes close to 0 . Table 1 displays the adjusting parameters $\left(\mathrm{r}^{2}, p 1, p 2\right.$ and RMSEP) from the PLS prediction model, which was applied to the validation set for the different created models using the noble electrodes. In order to make comparisons, the fitting parameters obtained for the validation samples when using non noble electrodes and the whole set of eight electrodes (noble and non-noble) are also displayed in Table 1.

\section{Insert here Table 1}

For Total Acidity, $\mathrm{r}^{2}$ and $p l$, values larger than 0.9 were observed for the validation set. Moreover, the best model was found when only noble electrodes were used. To determine $\mathrm{pH}$, a similar situation occurred with relatively good $\mathrm{r}^{2}$ and $p l$ values for all 
the combinations of electrodes tested. This contrasts with sugar content ( $\left.{ }^{\circ} \mathrm{Brix}\right)$ for which significant differences in prediction accuracy were found, based on the electrochemical information depending on the electrodes employed. When the whole set of electrodes or the noble electrodes was/were used, the obtained models were highly accurate and precise, whereas when the non noble electrodes were considered, the $\mathrm{r}^{2}$ and pl values were significantly worse.

To conclude, it can be established that the best models were obtained when using the electrochemical information from the noble electrodes. By way of example of the aforementioned accuracy, it can be statistically established from the PLS model and the adjusting parameters that medium concentrations of these parameters in the validation set can be determined using the electronic tongue with errors under $15 \%$. These results suggest the possibility of using an electronic tongue based on simple metallic electrodes to monitor the parameters used to evaluate grape ripeness, such as Total Acidity and ${ }^{\circ}$ Brix.

Inset here Figure 4

\section{Conclusions}

In summary, a study of the possible use of a voltammetric electronic tongue based on metallic electrodes to monitor grape ripeness has been reported. The electrochemical response and the physicochemical parameters Total Acidity, $\mathrm{pH}$ and ${ }^{\circ}$ Brix for seven varieties of grapes were determined. The PCA analysis shows that grape ripeness correlates with both the physic-chemical and voltammetric data, as also confirmed by the PLS studies. The PLS analyses were applied using 46 and 22 samples, which were utilized in the training steps and the validation steps, respectively. Three different PLS 
models were created for Total Acidity, $\mathrm{pH}$ and ${ }^{\circ}$ Brix using the information from all the electrodes, the noble ( $\mathrm{Pt}, \mathrm{Rh}, \mathrm{Ir}$ and $\mathrm{Au})$ and the non noble $(\mathrm{Cu}, \mathrm{Co}, \mathrm{Ag}$ and $\mathrm{Ni})$ electrodes. For parameters such as Total Acidity and $\mathrm{pH}$, all the created models proved accurate and precise, whereas the ${ }^{\circ}$ Brix values were much better predicted when the electrochemical information obtained from the noble electrodes was employed. One remarkable result relates to the possibility of using a simple electronic tongue to simultaneously monitor the Total Acidity and ${ }^{\circ}$ Brix parameters. In particular, the use of stable simple noble metallic electrodes, and the potential further implementation of an automatic cleaning step and small portable electronic equipment, make this electronic tongue a suitable system to monitor grape ripeness and to determine the harvesting date, which we believe can compete with traditional laboratory-based, reagent-consuming procedures.

\section{Acknowledgement}

The financial support from the Spanish Government (project MAT2012-38429-C04-01) and the Generalitat Valenciana (Valencian Regional Government; project PROMETEO/2009/016) is gratefully acknowledged.

\section{Bibliography}

Abdi. H., Williams, L.J. (2010). "Principal component analysis". Wiley Interdisciplinary Reviews: Computational Statistics, 2, 433-459.

Alcañiz, M., Vivancos, J.L., Masot, R., Ibañez, J., Raga, M., Soto, J., Martínez-Máñez, R. (2012). Design of an electronic system and its application to electronic tongues using variable amplitude pulse voltammetry and impedance spectroscopy. Journal of Food Engineering, 111, 122-128. 
Andrades, M. S., González-Sanjosé, M. L. (1995). Climatic influence in the maturation of the grape: study cultivars of Rioja and Madrid. Zubía monographic, 7, 79-102.

Apetrei, I.M., Rodríguez-Méndez, M.L., Apetrei, C., Nevares, I., del Alamo, M., de Saja J.A. (2012). Monitoring of evolution during red wine aging in oak barrels and alternative method by means of an electronic panel test. Food Research International, 45, 244-249.

Buratti, S., Ballabio, D., Giovanelli, G., Zuluanga Dominguez, C.M., Moles, A., Benedetti, S., Sinelli, N. (2011). Monitoring of alcoholic fermentation using near infrared and mid infrared spectroscopies combined with electronic nose and electronic tongue. Analytica Chimica Acta, 697, 67-74.

Buratti, S., Benedetti, S., Scampicchio, M., Pangerod, E.C. (2004). Characterizaton and classification of Italian Barbera wines by using an electronic nose and an amperometric electronic tongue. Analytica Chimica Acta, 525, 133-139.

Campos, I., Masot, R., Alcañiz, M., Gil, L., Soto, J., Vivancos, J.L., García-Breijo, E., Labrador, R.H., Barat, J.M., Martínez-Máñez, (2010). R. Accurate concentration determination of anions nitrate, nitrite and chloride in minced meat using a voltammetric electronic tongue. Sensors and Actuators B:Chem, 149, 71-78.

Campos, I., Alcañiz, M., Aguado, D., Barat, R., Ferrer, J., Gil, L., Marrakchi, M., Martínez-Máñez, R., Soto, J., Vivancos, J.L. (2012). A voltammetric electronic tongue as tool for water quality monitoring in wastewater treatment plants. Water Research, 46, $2605-2614$.

Cetó, X., Gutiérrez, J.M., Gutiérrez, M., Céspedes, F., Capdevila, J., Mínguez, S., Jiménez-Jorquera, C., del Valle, M. (2012). Determination of total polyphenol index in wines employing a voltammetric electronic tongue. Analytica Chimica Acta, 732, 172179. 
Chauchard, F., Codgill, R., Roussel, S., Roger, J. M., Bellon-Meurel, V. (2004). Application of LS-SVM to non-linear phenomena in NIR spectroscopy: development of a robust and portable sensor for acidity prediction in grapes. Chemometrics Intelligent Laboratory Systems, 71, 141-150.

Ciosek, P., Wróblewski, W. (2007). Sensor array for liquid sensing-Electronic tongue systems. Analyst, 132, 963-978.

Coombe, B. G. (1987). Distribution of solutes within the developing grape berry in relation to its morphology. American Journal of Enology and Viticulture, 38, 120-127.

De Jong, S. (1993). SIMPLS: An alternative approach to partial least squares regression. Chemometrics and Intelligent Laboratory Systems, 18, 251-263.

Del Valle, M. (2010). Electronic tongues employing electrochemical sensors. Electroanalysis, 22, 1539-1555.

Fernández-Novales, J., López, M. I., Sánchez, M. T., Morales, J., González Caballero, V. (2009). Shortwave-near infrared spectroscopy for determination of reducing sugar content during grape ripening, winemaking and aging of white and red wines. Food Research International, 42, 285-291.

Ferrer-Gallegoa, R., Hernández-Hierrob, J. M., Rivas-Gonzaloa, J.C., EscribanoBailóna, M. T. (2013). Evaluation of sensory parameters of grapes using near infrared spectroscopy. Journal of Food Engineering, 118, 333-339.

Gallardo, J., Alegret, S., Del Valle, M. (2005). Application of a potentiometric electronic tongue as a classification tool in food analysis. Talanta, 66, 1303-1309.

Gay, M., Apetrei, C., Nevares, I., Del Alamo, M., Zurro, J., Prieto, N., De Saja, J.A., Rodríguez-Méndez, M.L. (2010). Application of an electronic tongue to study the effect of the use of pieces of wood and micro-oxygenation in the aging of red wine. Electrochimica Acta, 55, 6782-6788. 
Geladi, P., Kowalski, B. R., (1986). Partial least-squares regression: a tutorial. Analytica Chimica Acta, 185, 1-17.

González-Sanjosé, M. L., Barrón, L. J. R., Junquera, B., Robredo, L. M. (1991). Application of principal component analysis to ripening indices for wine grapes. Journal of Food Composition and Analysis, 4, 245-255.

Gutés, A., Céspedes, F., del Valle, M., Louthander, D., Krantz-Rülcker, C., F. Winquist, F. (2006). A flow injection voltammetric electronic tongue applied to paper mill industrial waters. Sensors and Actuators B: Chem, 115, 390-395.

Gutierrez, M., Alegret, S., Del Valle, M. (2007). Potentiometric bioelectronic tongue for analysis of urea and alkaline ions in clinical samples. Biosensors and Bioelectronics, 22, $2171-2178$.

Gutiérrez, M., Domingo, C., Vila-Planas, J., Ipatov, A., Capdevila, F., Demming, S., Büttgenbach, S., Llobera, A., Jiménez-Jorquera, C. (2011). Hybrid electronic tongue for the characterization and quantification of grape variety in red wines. Sensors and Actuators B: Chem, 156, 695-702.

Jackson, R. S. (2000). Wine Science Principles, Practice, Perception, (2nd Edition), Chemical Constituents of Grapes and Wine (232-280). London.

Jones, G. V., Davis, R. E. (2000). Climatic influences on grapevine phenology, grape composition, and wine production and quality for Bordeaux, France. American Journal of Enology and Viticulture, 51, 249-261.

King, R. C., Sims, C. A., Moore, L.F., Bates, R. P. (1988). Effects of maturity, skins contact and carbonation on the quality of sterile filtered with Muscadine grape juice. Journal of Food Science, 53, 1474-1477. 
Kirsanov, D., Mednova, O., Vietoris, V., Kilmartin, P. A., Legin, A. (2012). Towards reliable estimation of an "electronic tongue" predictive ability from PLS regression models in wine analysis. Talanta, 90, 109-116.

Labrador, R. H., Olsson, J., Winquist, F., Martínez-Máñez, R., Soto, J. (2009). Determination of bisulfites in wines with an electronic tongue based on pulse voltammetry. Electroanalysis, 21, $612-617$.

Labrador, R., Soto, J., Martínez-Máñez, R., Gil, L. (2009). An electronic tongue for qualitative and quantitative analyses of anions in natural waters. Journal of Applied Electrochemistry, 39, 2505-2511.

Larraín, M., Guesalaga, A. R., Agosin, E. (2008). A multipurpose portable instrument for determining ripeness in wine grapes using NIR spectroscopy. IEEE Transactions on Instrumentation and Measurement, 57, 294-302.

Legin, A., Rudnitskaya, A., Lvova, L., Vlasov, Y., Di Natale, C., D’Amico, A. (2003). Evaluation of Italian wine by the electronic tongue: recognition, quantitative analysis and correlation with human sensory perception. Analytica Chimica Acta, 484, 33-44.

Lorenz, J.K., Reo, J.P., Hendl, O., Worthington, J.H., Petrossian, V.D. (2009). Evaluation of taste sensor instrument (electronic tongue) for use in formulation development. International Journal of Pharmaceutics, 367, 65-72.

Lvova, L., Martinelli, E., Dini, F., Bergamini, A., Paolesse, R., Di Natale, C., D'Amic, A. (2009). Clinical analysis of human urine by means of potentiometric electronic tongue. Talanta, 77, 1097-1104.

Martínez-Máñez, R., Sancenón, F. (2006). Chemodosimeters and 3D inorganic functionalised hosts for the fluoro-chromogenic sensing of anions. Chem. Soc. Rev. $250,3081-3093$ 
Michelhaugh, S.L., Bhardwaj, C., Cali, G.J., Bravo, B.G., Bothwell, M.E., Berry, G.M., Soriaga, M.P. (1991). The influence of chemisorbed organic monolayers on electrode surface oxidation. Corrosion, 47, 322-328.

Mimendia, A., Gutierrez, J.M., Leija, L., Hernandez, P.R., Favari, L., Munoz, R., del Valle, M. (2010). A review of the use of the potentiometric electronic tongue in the monitoring of environmental system. Environmental Modelling \& Software, 25, 10231030.

Olsson, J., Winquist, F., Lunsdtröm, I. (2004). A self-polishing electronic tongue. Sensors and Actuators B:Chem, 118, 461-465.

Palacios, J., Cea, P., Cancer M., Martínez, L. M., Avenoza, A. (1986). Evolution of ripening and maturity indices in Rioja wines. I.E.R. 8

Peynaud, E. (1989). Winemaking Practice. In Mundi-Prensa. Madrid. Spain.

Pigani, L., Culetu, A., Ulrici, A., Foca, G., Vignali, M., Seeber, R. (2011). Pedot modified electrodes in amperometric sensing for analysis of red wine samples. Food Chemistry, 129, 226-233.

Robredo, L.M., Junquera, B., González-Sanjosé, M.L., Barrón, L.J. (1991). Biochemical events during ripening of grape berries. Italian Journal of Food Science, 3, $173-180$.

Rudnitskaya, A., Ehlert, A., Legin, A., Vlasov, Y., Buttgenbach, S. (2001). Multisensor system on the basis of an array of non-specyfic chemical sensors and artificial neural networks for determination of inorganic pollutants in a model groundwater. Talanta, 55, $425-431$.

Santonico, M., Bellincontro, A., De Santis, D., Di Natale, C., Mencarelli, F. (2010). Electronic nose to study postharvest dehydration of wine grapes. Food Chemistry, 121, 789-796. 
Scampicchio, M., Ballabio, D., Arecchi, A., Cosio, S.M., Mannino, S. (2008). Amperometric electronic tongue for food analysis. Microchimica Acta, 163, 11-21.

Soriaga, M. P., White, J. H., Song, D., Chia, V. K. F., Arrhenius, P. O., Hubbard, A. T. (1985). Surface coordination chemistry of platinum studied by thin-layer electrodes. Surface chemical reactivity of aromatic and quinonoid compounds Adsorbed in specific orientational states. Inorganic Chemistry, 24, 73-79.

Wilson, A.D., Baietto, M. (2011). Advances in electronic-nose technologies developed for biomedical application. Sensors, 11, 1105-1176.

Winquist, F., Lundström, I., Wide, P. (1999). The combination of an electronic tongue and an electronic nose. Sensors and Actuators B: Chem, 58, 512-517.

Zhang, W., Turner, K.L. (2005). Application of parametric resonance amplification in a single-crystal silicon micro-oscillator based mass sensor. Sensors and Actuators A:Phys, $122,23-30$. 

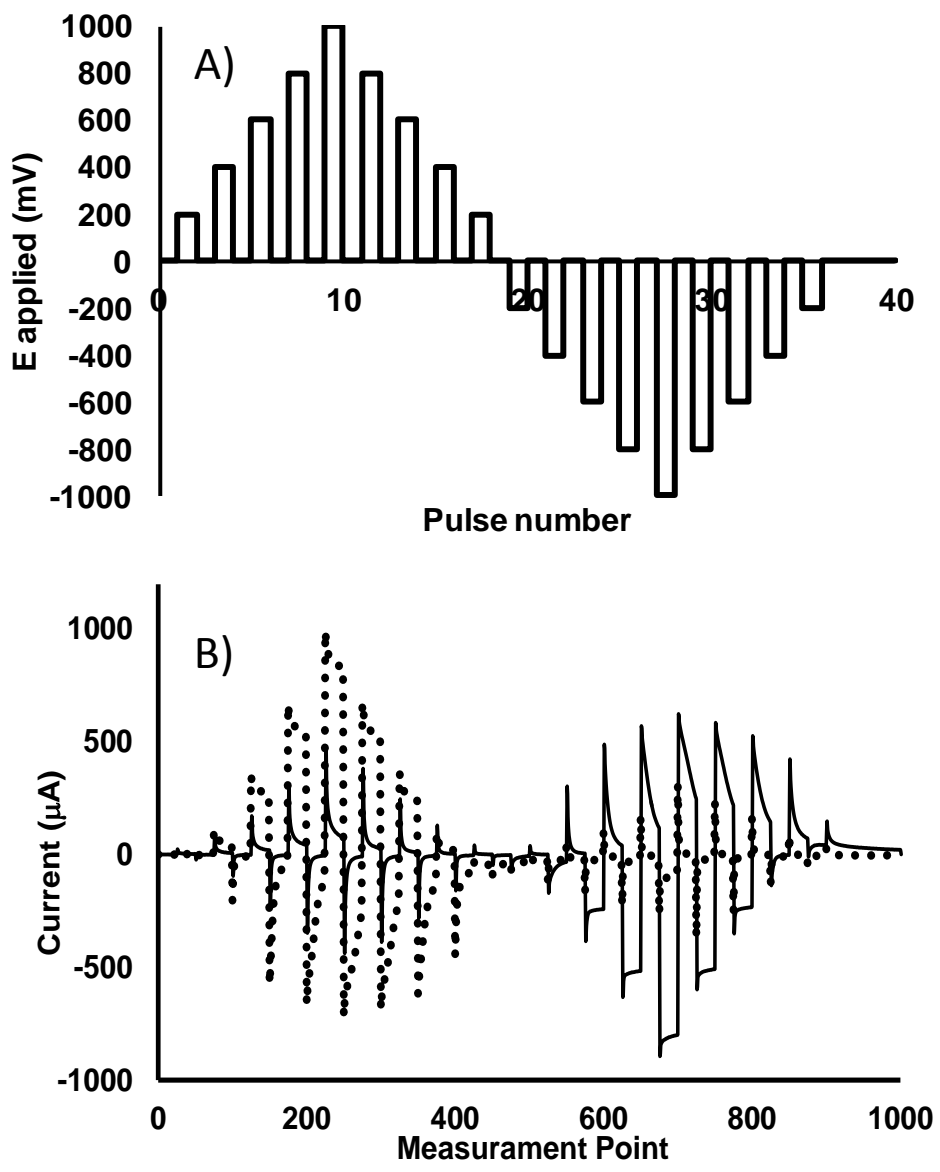
Figure1 Legend

Figure 1 A) Waveform applied to carry out the measurement and B) current response for a Macabeo grape using Pt (continuous line) and $\mathrm{Ag}$ as electrodes (dotted line). 

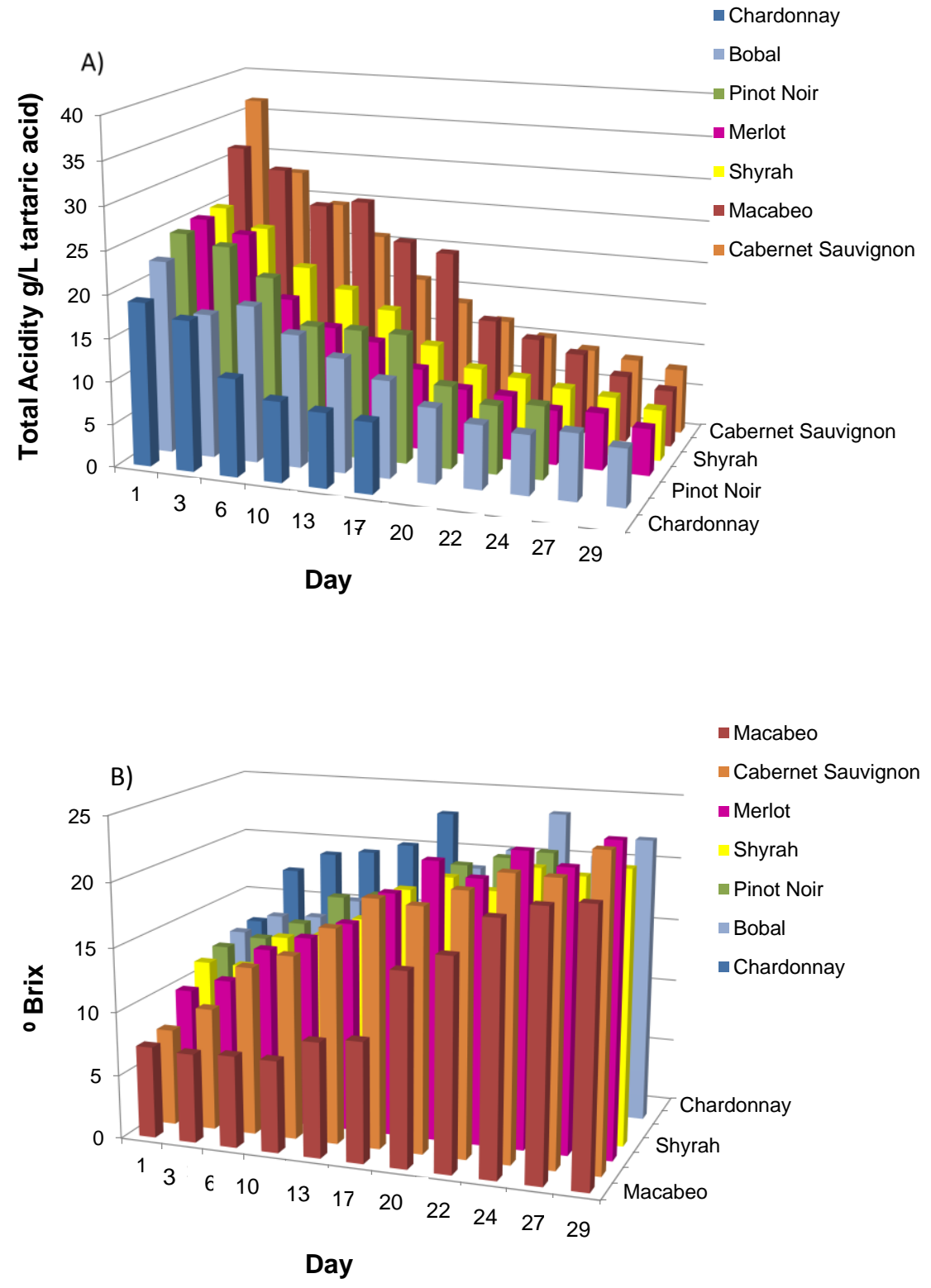
Figure2 Legend

Figure 2 A) Total Acidity and B) ${ }^{\circ}$ Brix values for the grapes studies as a function of the sampling day. 

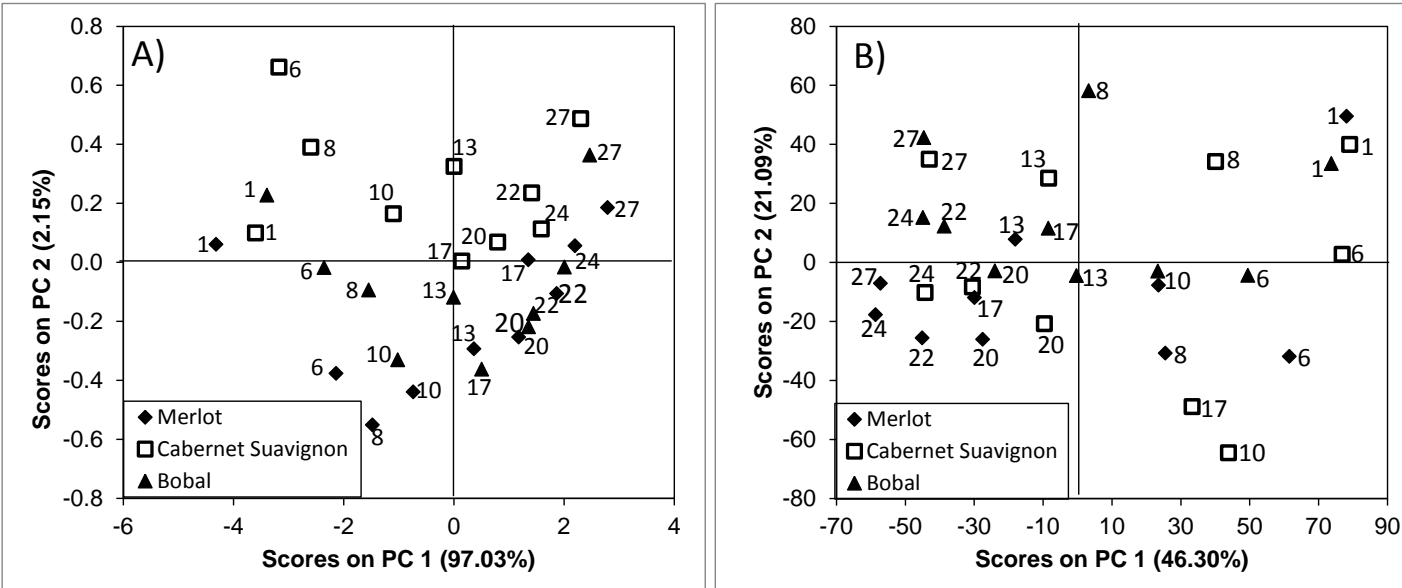
Figure 3. PCA score plot created for three different varieties of grapes: Merlot (diamond), Cabernet Sauvignon (square) and Bobal (triangle) from a) from the physicchemical parameters and $b$ ) data from the electronic tongue (data from noble metal electrodes were used). The number that appears close to each point is the day when the samples were measured. 
Figure 4. PLS prediction model applied to the 22 validation samples for A) Total Acidity, B) $\mathrm{pH}$ and C) ${ }^{\circ}$ Brix. The plot also shows the 46 samples used for training the model. Only the electrochemical information obtained from noble electrodes was considered in this plot. 
Figure 4
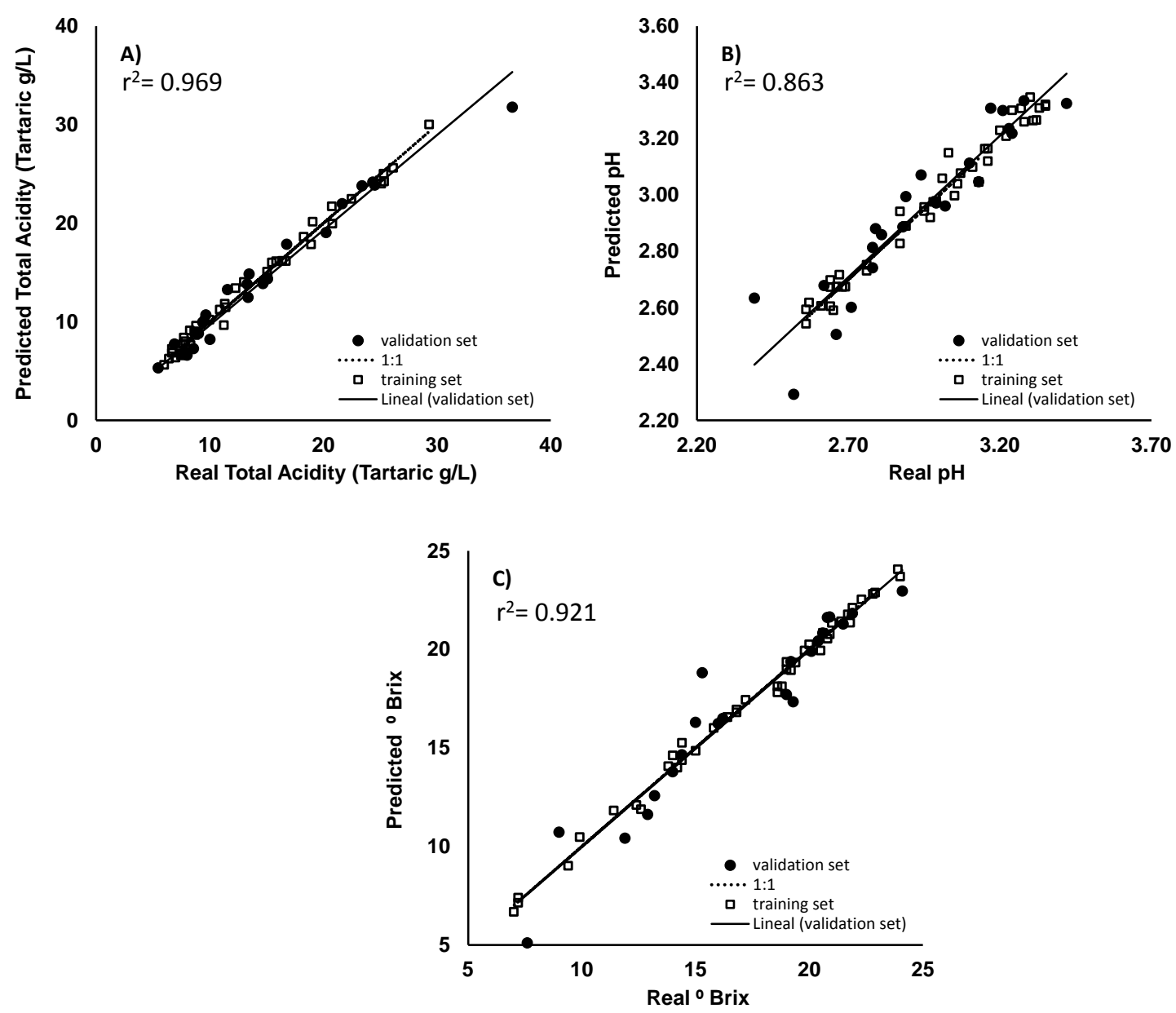
Table 1. Adjusting parameters $\left(r^{2}, p 1, p 2\right.$ and RMSEP) from the PLS prediction models for levels of Total Acidity, $\mathrm{pH}$ and ${ }^{\circ}$ Brix in validation samples from grape ripeness using different electrodes combination.

\begin{tabular}{clcccc} 
& & $r^{2}$ & $p l$ & $p 2$ & RMSEP \\
\hline \multirow{3}{*}{ 8 electrodes } & Total Acidity & 0.956 & 0.947 & 0.486 & 1.60 \\
& $\mathrm{pH}$ & 0.857 & 0.929 & 0.217 & 0.09 \\
& ${ }^{\circ}$ Brix & 0.903 & 1.069 & -1.401 & 1.55 \\
\hline \multirow{2}{*}{ Noble } & Total Acidity & 0.969 & 0.919 & 0.855 & 1.41 \\
& $\mathrm{pH}$ & 0.863 & 0.995 & 0.023 & 0.10 \\
& ${ }^{\circ}$ Brix & 0.921 & 1.014 & -0.321 & 1.28 \\
\hline \multirow{3}{*}{ Non-noble } & Total Acidity & 0.952 & 0.901 & -1.443 & 1.68 \\
& pH & 0.863 & 0.921 & 0.232 & 0.10 \\
& ${ }^{\circ}$ Brix & 0.750 & 0.979 & -0.062 & 2.46 \\
\hline
\end{tabular}


Table S1
Click here to download Supplementary material for online publication only: Supporting Information.docx

Table S1
Click here to download Supplementary material for online publication only: Supporting Information.docx

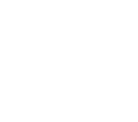
. .

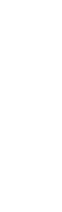
. 更 更 更 更 更 更 更 更 